\title{
Scalar Implicatures with Alternative Semantics
}

\author{
Ezra Keshet \\ Massachusetts Institute of Technology
}

\section{Introduction}

This paper examines several challenges to the standard Horn-Scale analysis of scalar implicature and proposes a new system that addresses these challenges, based on the Alternative Semantics of Kratzer and Shimoyama (2002).

\section{Standard Analysis}

One standard account of scalar implicature proposes that scalar items are associated with linguistically available scales, called Horn Scales after Horn (1972). To generate implicatures for a sentence containing a scalar item, one must consider the alternative sentences where the scalar item has been replaced with an item from its scale. All such sentences that are stronger are implicated to be false:

(1) $\operatorname{Alt}(\phi)=\left\{\phi^{\prime}: \phi\right.$ contains scalar item $s$ and $\phi^{\prime}$ is the same as $\phi$ except that $s$ is replaced with an item from the Horn Scale for $s\}$

(2) Implicatures Generated: $\forall \phi^{\prime} \in \operatorname{Alt}(\phi) .\left(\phi^{\prime} \Rightarrow \phi\right) \rightarrow \neg \phi^{\prime}$

For example, an implicature for (3a) is given in (3b):

(3) a. Paul read three books. $\rightsquigarrow$

b. Paul did not read four books.

The scalar item three is part of the Horn Scale consisting of at least the natural numbers, so the relevant alternatives to (3a) are those sentences where three is replaced with another number:

(4) Horn Scale for three: $\{$ one, two, three, four, five, ... $\}$

(5) Alt (Paul read three books) $=$

$\left\{\begin{array}{l}\text { Paul read one book, Paul read two books, } \\ \text { Paul read three books, Paul read four books, } \\ \text { Paul read five books , ... }\end{array}\right\}$

Since Paul read four books is such an alternative and furthermore entails (3a), the implicature is generated that Paul did not read four books:

(6) Paul read four books. $\Rightarrow$ Paul read three books.

(7) Paul did not read four books. (by 2)

Thanks to Danny Fox, Irene Heim, Gennaro Chierchia, Kai von Fintel, Tamina Stephenson, and the members of the MIT Workshop on Syntax and Semantics, Fall 2005 


\section{Challenges}

This standard approach does not generate the correct results in every case, however. For the remainder of the paper, I will concentrate on two instances where the standard proposal fails. These cases will motivate a new approach to scalar implicature, detailed in Section 6 below.

\subsection{Comparative Problem}

When a scalar item like three is embedded in a comparative expression, the implicature it normally gives rise to in a simpler context often disappears. For instance, (8a) does not actually generate the implicature in $(8 b)$ :

$$
\text { (after Krifka 1999) }
$$

a. Paul read more than three books. $\psi$

b. Paul did not read more than four books.

However, if you were to go through the exact steps of the standard proposal used above, you would generate this (fallacious) implicature. Paul read more than three books is a stronger alternative of (8a) as defined in (1):

(9) Alt (Paul read more than three books) $=$ $\left\{\begin{array}{l}\text { Paul read more than one book, Paul read more than two books, } \\ \text { Paul read more than three books, Paul read more than four books, } \\ \text { Paul read more than five books , ... }\end{array}\right\}$

(10) Paul read more than four books. $\Rightarrow$ Paul read more than three books.

Therefore, by (2):

(11) Paul did not read more than four books.

This incorrect prediction is a challenge to be overcome by any theory of scalar implicature.

\subsection{Disjunction Problem}

Another case where the standard proposal makes an incorrect prediction was pointed out by Chierchia (2002). When one clause of a disjunction contains a scalar item, the standard account predicts that the other clause of the disjunction be implicated to be false. For instance, (12a) is predicted incorrectly to have the implicature in (12b).

(12) a. Paul read The New York Times or some of the books. $\psi_{\rightarrow}$

b. Paul did not read The New York Times.

The reasoning goes as follows - (15a) is a stronger alternative to (12a): 
(13) Horn Scale for some: $\{$ some, most, all $\}$

(14) Alt(Paul read The New York Times or some of the books) $=$ $\left\{\begin{array}{l}\text { Paul read The New York Times or most of the books } \\ \text { Paul read The New York Times or all of the books }\end{array}\right\}$

(15) a. Paul read The New York Times or all of the books. $\Rightarrow$ b. Paul read The New York Times or some of the books.

Therefore, by (2):

(16) Paul did not read The New York Times or all of the books.

And if you apply DeMorgan's Law:

Paul did not read The New York Times and Paul did not read all of the books.

Therefore (taking the first clause of the conjunction):

(18) Paul did not read The New York Times.

Once again, this fallacious prediction should be avoided in a theory of scalar implicature.

\section{Intuitive Proposal}

To address these challenges, I will start with a simple observation, which is also found in Kratzer (2005). ${ }^{1}$ First, it has been noted that scalar sentences having the word only and focus on their scalar item roughly paraphrase the strengthened meanings of the same sentences without only (Fox 2004). (The strengthened meaning is the meaning of the original sentence plus its scalar implicatures.) For instance, (19) roughly paraphrases the strengthened meaning of (3a):

(19) Paul only read three books.

Building on this idea, the observation I will base my analysis on is that such paraphrases where the indefinite involved takes scope over the rest of the sentence seem to avoid the problems mentioned above:

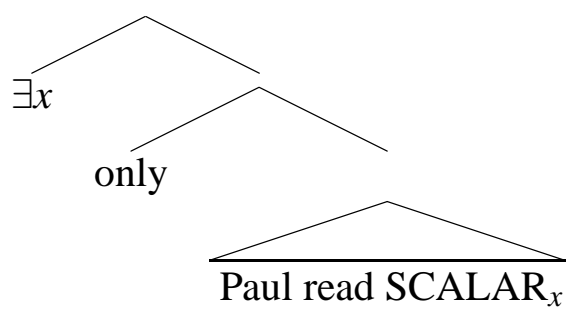

In simple cases, paraphrases with high scope for the indefinite seem to match the expected strengthened meaning:

\footnotetext{
${ }^{1}$ Kratzer (2005) proposes a similar line of attack, especially for the comparative puzzle, in her 2005 LSA Summer Institute handout. I have tried to expand this analysis to other puzzles and flesh out the technical details.
} 
(21) a. Paul read three books.

b. There is a group $x$ of three books : Paul only read $x$.

(22) a. Paul read some books.

b. There is a group $x$ that is a proper subset of the books : Paul only read $x$.

a. Paul read War and Peace or The Brothers Karamazov.

b. There's a group $x$ containing one book, which is either War and Peace or The Brothers Karamazov: Paul only read $x$.

Also, in the comparative and complex disjunction cases, the paraphrases seem to match the actual strengthened meanings more closely than the meanings generated by the standard proposal:

(24) a. Paul read more than two books.

b. There is a group $x$ of more than two books : Paul only read $x$.

(25) a. Paul read The New York Times or some of the books.

b. There is a group $x$ such that $x$ is the group containing only The New York Times or $x$ is a proper subset of the books : Paul only read $x$.

Having made this observation, the question arises of how a structure suggested by these paraphrases can be implemented syntactically and semantically. The next section presents some background work that will provide the basis for the proposal given in Section 6.

\section{Background}

In this section, I will adapt a system proposed by Kratzer and Shimoyama (2002). In their system, the normal semantic values for many items of type $\sigma$ (or $\langle\sigma t, t\rangle$ ) are replaced by sets containing items of type $\sigma$. For the remainder of the paper, I will refer to such items as being of type type $\{\sigma\}$ or subsets of $D_{\sigma}$. For instance, a simple indefinite such as $a$ book has the following denotation:

$$
\left.\llbracket \text { a book } \rrbracket=\left\{x \in D_{e}: x \text { is a book }\right\} \text { (type }\{e\}, \subseteq D_{e}\right)
$$

A book denotes the set of individuals that are books.

\subsection{Hamblin Functional Application}

In the Kratzer and Shimoyama system, these denotation sets combine pointwise with predicates via the following composition rule:
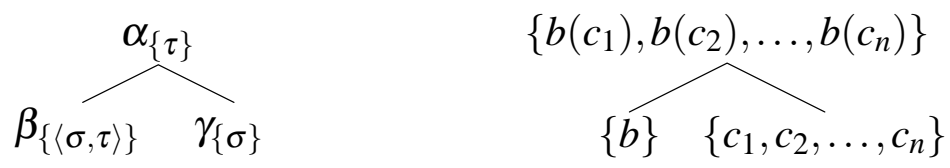
Hamblin Functional Application

If $\alpha$ is a branching node with daughters $\beta$ and $\gamma$, and $\llbracket \beta \rrbracket \subseteq D_{\langle\sigma, \tau\rangle}$ and $\llbracket \gamma \rrbracket \subseteq D_{\sigma}$, then $\llbracket \alpha \rrbracket=\left\{a \in D_{\tau}: \exists b \exists c[b \in \llbracket \beta \rrbracket \& c \in \llbracket \gamma \rrbracket \& a=b(c)]\right\}$.

Basically, the rule applies each of the predicates in set $\beta$ to each of the individuals in set $\gamma$. The results of these operations form the set $\alpha$.

For instance, in the example below, the singleton set representing the denotation of the verb read combines with the set representing the meaning of the phrase a book:

\section{read a book}

$\{$ read War \& Peace, read The Brothers Karamazov, ... $\}$

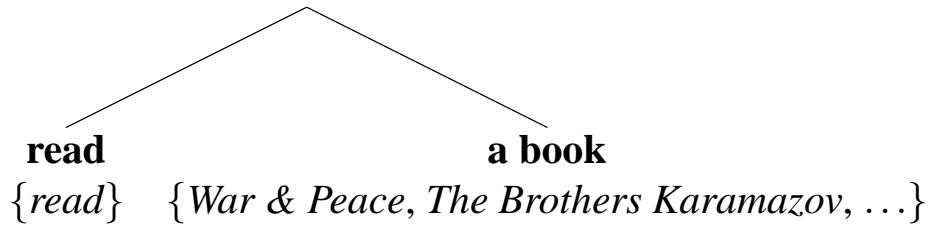

This new set, a set of predicates, can combine with another at the next level up:

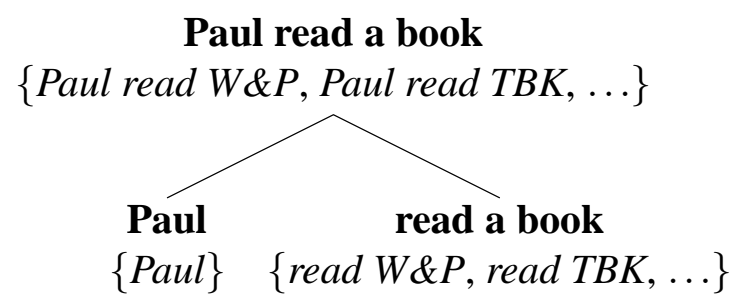

This process continues, until at the the top of a sentence you are left with a set of propositions.

\subsection{Sentential Quantifier}

The normal meaning of the sentence Paul read a book, however, is not a set of propositions, but a single proposition. The correct meaning is obtained in this system by applying the sentential quantifier $\exists$ (using the standard Functional Application Rule):

$$
\llbracket \exists \alpha \rrbracket=\left\{\lambda w^{\prime} . \exists p\left[p \in \llbracket \alpha \rrbracket \& p\left(w^{\prime}\right)=1\right]\right\} \text { for } \llbracket \alpha \rrbracket \subseteq D_{s t}
$$

$\exists$ takes a set of propositions and returns a singleton set containing the proposition that is true when one of the original propositions in the set is true. ${ }^{2}$

\subsection{Plural Individuals}

Another bit of background machinery that the proposal below requires is the idea of plural individuals. Plural individuals (Link 1983) represent the mereological sums

\footnotetext{
${ }^{2}$ Kratzer and Shimoyama (2002) also propose generalized quantifiers that take sets of individuals. I believe that the presence of such a quantifier would have the same effect as reversing the order of an exhaustive operator and sentential quantifier - see Section 7.1.
} 
of singular individuals in $D_{e}$ and have some properties analogous to sets (e.g., cardinality, part-of and proper part-of relations, and membership). Using this concept, we can now define the words of our example sentence:
a. $\llbracket$ books $\rrbracket=\left\{x \in D_{e}: x\right.$ is two or more books $\}$ (type $\{e\}$ )
b. $\llbracket$ three $\left.\rrbracket=\left\{x \in D_{e}:|x|=3\right]\right\}$ (type $\{e\}$ )
c. $\llbracket \operatorname{read} \rrbracket=\left\{\left[\lambda y \in D_{e} . \lambda x \in D_{e} . x\right.\right.$ reads $\left.y\right\}$ (type $\{\langle e,\langle e, t\rangle\rangle\}$ )
d. $\llbracket$ Paul $\rrbracket=\{$ Paul $\}$ (type $\{e\}$ )

Note that the standard Predicate Modification rule (Heim and Kratzer 1998) will work correctly on sets of alternatives:

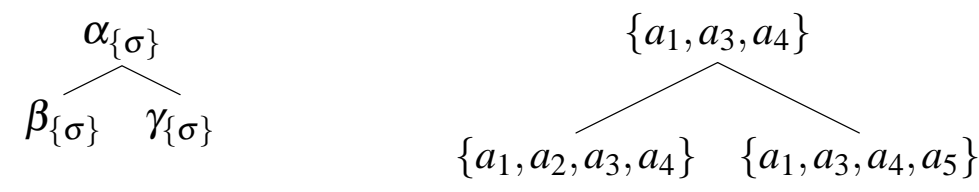

Predicate Modification

If $\alpha$ is a branching node with daughters $\beta$ and $\gamma$, and $\llbracket \beta \rrbracket \subseteq D_{\{\sigma\}}$ and $\llbracket \gamma \rrbracket$ $\subseteq D_{\{\sigma\}}$, then $\llbracket \alpha \rrbracket=\llbracket \beta \rrbracket \cap \llbracket \gamma \rrbracket$.

This is the rule used to combine three and books.

Now we can derive the complete meaning of a simple sentence:

(35) $\llbracket \exists$ Paul read three books. $\rrbracket=$ A statement in the following set is true: \{Paul read $x: x$ is the sum of exactly three books\}.

\subsection{Context}

The last concept that the new proposal requires is a particular (but not unusual) notion of context. Every sentence is assumed to be uttered in relation to a subset of $D_{s t}$ that I will call the focus set, which can be thought of as the Hamblin denotation of a question. ${ }^{3}$ For instance, the question in (36a) sets up the focus set in (36b):

a. What did Paul read last night?

b. \{Paul read War and Peace last night, Paul read The Brothers Karamazov last night, Paul read The New York Times last night, Paul read $W \& P \oplus$ NYT last night, ... $\}$

\section{Proposal}

With the system outlined in the previous section in place, I can now describe the actual proposal. The idea is that scalar implicatures arise when a sentence contains a

\footnotetext{
${ }^{3}$ As far as I can tell, this idea goes back to Collingwood (1940), as quoted in von Fintel (1995):

(i) Every statement that anybody ever makes is made in answer to a question (p. 14).
} 
silent exhaustive operator (Groenendijk and Stokhof 1984, Krifka 1995, Fox 2004), which scopes below the existential closure of indefinites (Heim 1982, Kratzer and Shimoyama 2002) and disjunction (Rooth and Partee 1982). This operator is usually assumed to be optional, which explains why implicatures can be canceled.

My definition of the exhaustive operator $E x h$ (adapted from those referenced above) is:

$\llbracket E x h \rrbracket=\left\{\left[\lambda p \in D_{s t} . \lambda w^{\prime} \in D_{s} \cdot p\left(w^{\prime}\right) \& \forall f \in F\left[f\left(w^{\prime}\right) \rightarrow(p \Rightarrow f)\right]\right]\right\}$, where $F$ is the focus set.

When taking a proposition $p, E x h$ means that $p$ (often call the prejacent) is true and the only true propositions in the focus set are those that are entailed by $p .^{4}$

Imagine that there are three choices of reading material in the focus set established by the question in (38a): War and Peace, The New York Times, and The Brothers Karamazov. Given this focus set, the meaning comes out as follows:

a. What did Paul read last night?

b. $\exists$ Exh Paul read War \& Peace and The Brothers Karamazov.

c. A statement from this set is true:

\{Paul read War \& Peace and The Brothers Karamazov but not The New York Times. $\}$

War \& Peace and The Brothers Karamazov denotes the mereological sum of the two books mentioned. The exhaustive operator strengthens the meaning of the proposition in the following way: the alternative proposition where Paul read the third available piece of reading material, namely The New York Times, is asserted to be false.

\subsection{Numerals}

Next consider a simple scalar sentence containing a numeral, once again in response to the same question. Also, recall the desired paraphrase for such a sentence:

(39) What did Paul read last night?

(40) a. Paul read three books last night.

b. There's a group $x$ of three books : Paul only read $x$ last night.

Finally, we can see how such a paraphrase is possible. The existential that scopes above all else comes from the $\exists$ operator. This is possible in the Kratzer and

\footnotetext{
${ }^{4}$ This definition differs from most definitions of the overt exhaustive operator only in that the plain meaning of the prejacent is asserted to be true, rather than presupposed. This cannot be the only difference, however, since there are positions where I have assumed Exh is benign that are essentially ungrammatical for only:

(ii) *Paul only read more than three books last night.

My only thought on the issue is that perhaps there is some sort of restriction on the scope of overt only.
} 
Shimoyama system even without proposing that the indefinite itself moves in the syntax. A fuller derivation is given below:
a. $\exists$ Exh Paul read three books last night.
b. $\exists E x h\{$ Paul read $x$ last night $: x \in \llbracket$ book $\rrbracket \&|x|=3\}$

By Hamblin Functional Application, you combine Exh and the set pointwise:

c. $\exists\{E x h$ Paul read $x$ last night $: x \in \llbracket$ book $\rrbracket \&|x|=3\}$

Now, if we assume there are only four books under discussion:

d. One of these statements is true:

$$
\left\{\begin{array}{l}
\text { Paul only read } b_{1} \oplus b_{2} \oplus b_{3}, \\
\text { Paul only read } b_{1} \oplus b_{3} \oplus b_{4}, \\
\text { Paul only read } b_{1} \oplus b_{2} \oplus b_{4}, \\
\text { Paul only read } b_{2} \oplus b_{3} \oplus b_{4}
\end{array}\right\}
$$

\subsection{Some}

Similarly, in a sentence with the scalar item some, the desired result is obtained with the following new definition:

$$
\begin{aligned}
& \llbracket \text { some of the } \rrbracket=\left[\lambda X \subseteq D_{e} \cdot\{x \in X: \exists y \in X[y \nless x]\}\right] \\
& \text { (type }\langle\{e\},\{e\}\rangle)
\end{aligned}
$$

This definition operates on a set and therefore is applied using normal Functional Application. It basically returns its argument set minus the largest element, defined in terms of the plural individual part-of relation. A richer definition of some of the books might include the fact that it only includes groups containing a small proportion of the books, but for the purpose of deriving the simple not all implicature, this definition suffices.

In our four-book world the meanings of the terms are as follows:

$$
\begin{aligned}
& \text { a. 【books 》 = } \\
& \left\{\begin{array}{l}
b_{1} \oplus b_{2}, b_{1} \oplus b_{3}, b_{1} \oplus b_{4}, b_{2} \oplus b_{3}, b_{2} \oplus b_{4}, b_{3} \oplus b_{4}, \\
b_{1} \oplus b_{2} \oplus b_{3}, b_{1} \oplus b_{3} \oplus b_{4}, b_{1} \oplus b_{2} \oplus b_{4}, b_{2} \oplus b_{3} \oplus b_{4}, \\
b_{1} \oplus b_{2} \oplus b_{3} \oplus b_{4}
\end{array}\right\} \\
& \text { b. 【 some of the books 》= } \\
& \left\{\begin{array}{l}
b_{1} \oplus b_{2}, b_{1} \oplus b_{3}, b_{1} \oplus b_{4}, b_{2} \oplus b_{3}, b_{2} \oplus b_{4}, b_{3} \oplus b_{4}, \\
b_{1} \oplus b_{2} \oplus b_{3}, b_{1} \oplus b_{3} \oplus b_{4}, b_{1} \oplus b_{2} \oplus b_{4}, b_{2} \oplus b_{3} \oplus b_{4}
\end{array}\right\}
\end{aligned}
$$

The group including all four books is the only one missing from this second set.

Now, first note what the sentence means when the exhaustive operator is absent:
a. $\exists$ Paul read some of the books last night.
b. $\exists\{$ Paul read $x$ last night: $x \in \llbracket$ some of the books $\rrbracket\}$ 
This meaning simply makes no claim about the sum of all books; therefore it is not false in a world where Paul read all of the books. Similarly, it makes no claim about him reading or not reading any magazines or newspapers.

Once the Exh is added, however, we derive the strengthened meaning:

a. $\exists$ Exh Paul read some of the books last night.

$$
\text { b. } \exists\left\{\begin{array}{l}
\text { Paul only read } b_{1} \oplus b_{2}, \\
\text { Paul only read } b_{1} \oplus b_{3}, \\
\text { Paul only read } b_{1} \oplus b_{4}, \\
\text { Paul only read } b_{2} \oplus b_{3}, \\
\text { Paul only read } b_{2} \oplus b_{4}, \\
\text { Paul only read } b_{3} \oplus b_{4}, \\
\text { Paul only read } b_{1} \oplus b_{2} \oplus b_{3}, \\
\text { Paul only read } b_{1} \oplus b_{3} \oplus b_{4}, \\
\text { Paul only read } b_{1} \oplus b_{2} \oplus b_{4}, \\
\text { Paul only read } b_{2} \oplus b_{3} \oplus b_{4},
\end{array}\right\}
$$

This means that one group of books not containing all the books is such that Paul read only that group. If magazines or newspapers were added to the focus set, then Paul must not have read those either.

\subsubsection{Some + Plural Problem}

This example warrants a small excursus into another problem encountered by some other systems for scalar implicature. Some systems generate the following fallacious implication:

(46) Paul read some of the books. $\rightsquigarrow$ Paul didn't read more than two books. 5

Groenendijk and Stokhof (1984) have this problem due to the fact that their exhaustive operator limits meanings to the set of minimal possible answers. Example (47) shows the set of minimal values of the plural indefinite some of the books in a four-book world; this set happens to be equivalent to exactly two of the books:

$$
\left\{\begin{array}{l}
\left\{b_{1}, b_{2}, b_{1} \oplus b_{2}\right\}, \\
\left\{b_{1}, b_{3}, b_{1} \oplus b_{3}\right\}, \\
\left\{b_{1}, b_{4}, b_{1} \oplus b_{4}\right\}, \\
\left\{b_{2}, b_{3}, b_{2} \oplus b_{3}\right\}, \\
\left\{b_{2}, b_{4}, b_{2} \oplus b_{4}\right\}, \\
\left\{b_{3}, b_{4}, b_{3} \oplus b_{4}\right\}
\end{array}\right\}
$$

If such a set includes a group of three books, such as in (48), it will necessarily be a superset of one of the sets in (47), because if you read a group of books, you also read all subgroups of that group:

$$
\left\{b_{1}, b_{2}, b_{3}, b_{1} \oplus b_{2}, b_{2} \oplus b_{3}, b_{1} \oplus b_{2} \oplus b_{3}\right\}
$$

\footnotetext{
${ }^{5}$ This problem was pointed out to me by Danny Fox
} 
Just for completeness, notice that any smaller set, such as the set in (49) will not satisfy the pluralness of the indefinite:

$$
\left\{b_{1}\right\}
$$

Fox (2006) runs into the same problem for a slightly different reason. His exhaustive operator works on maximal exclusions, where a maximal exclusion is the largest set of alternatives that can be excluded by an exhaustive operator without falsifying the prejacent. For some of the books, every maximal exclusion must leave out one group of books of size two in order not to falsify the pluralness of the prejacent. However, any group of size three or greater can safely be included in all maximal exclusions without falsifying the prejacent. Since under this theory the propositions in the intersection of all maximal exclusions are implicated to be false, there is no group of size three or greater that will satisfy the exhaustified meaning.

As shown in the section above, the new system described in this paper does not suffer from this problem. Some of the books, even when strengthened by the exhaustive operator, is compatible with groups of books of size greater than two.

\subsection{Comparatives}

Turning now to the first of the challenges mentioned in Section 3 above, Kratzer (2005) suggests how an analysis along these lines might solve the comparative problem. To see how it works in the current framework, consider this definition for the comparative expression more than two:

$$
\left.\llbracket \text { more than two } \rrbracket=\left\{x \in D_{e}:|x|>2\right\} \text { (type }\{e\}\right)
$$

The denotation of more than two is simply the set of all plural individuals of cardinality greater than two.

In our world with only four books, this meaning applies as follows:

$$
\begin{aligned}
& \text { a. } \exists E x h \text { Paul read more than two books last night. } \\
& \text { b. } \exists E x h \text { \{Paul read } x \text { last night }: x \in \llbracket \text { book } \rrbracket \&|x|>2\} \\
& \text { c. } \exists\{E x h \text { Paul read } x \text { last night }: x \in \llbracket \text { book } \rrbracket \&|x|>2\} \\
& \text { d. } \exists\left\{\begin{array}{l}
\text { Paul only read } b_{1} \oplus b_{2} \oplus b_{3}, \\
\text { Paul only read } b_{1} \oplus b_{3} \oplus b_{4}, \\
\text { Paul only read } b_{1} \oplus b_{2} \oplus b_{4}, \\
\text { Paul only read } b_{2} \oplus b_{3} \oplus b_{4}, \\
\text { Paul only read } b_{1} \oplus b_{2} \oplus b_{3} \oplus b_{4}
\end{array}\right\}
\end{aligned}
$$

Since we are exhaustifying over specific groups of books and only then applying the existential closure, this approach does not run into the same problem as the standard analysis. Any appropriate group might have been read, including groups of any size above the given numeral. 


\subsection{Disjunction Problem}

Taking the standard meaning of or as set union, we can tackle the disjunction problem: 6

$$
\llbracket \text { or } \rrbracket=\left[\lambda X \subseteq D_{\sigma} \cdot \lambda Y \subseteq D_{\sigma} \cdot X \cup Y\right](\text { type }\langle\{\sigma\},\langle\{\sigma\},\{\sigma\}\rangle\rangle)
$$

Or also applies to sets (using normal Functional Application); it takes two sets and returns their union. For instance, the meaning for a sentence with two singleton indefinites is derived as follows:

a. $\exists$ Exh Paul read The New York Times or The Boston Globe last night.

b. $\exists\{E x h$ Paul read $x$ last night $: x \in\{$ The New York Times, The Boston Globe

c. $\exists\left\{\begin{array}{l}\text { Paul only read The New York Times last night, } \\ \text { Paul only read The Boston Globe last night }\end{array}\right\}$

The derivation is the same when one of indefinites has more alternatives in its denotation set:

a. $\exists E x h$ Paul read The New York Times or some of the books.

b. $\exists\left\{\begin{array}{l}\text { Paul only read The New York Times, } \\ \text { Paul only read } b_{1} \oplus b_{2}, \\ \text { Paul only read } b_{1} \oplus b_{3}, \\ \text { Paul only read } b_{1} \oplus b_{4}, \\ \text { Paul only read } b_{2} \oplus b_{3}, \\ \text { Paul only read } b_{2} \oplus b_{4}, \\ \text { Paul only read } b_{3} \oplus b_{4}, \\ \text { Paul only read } b_{1} \oplus b_{2} \oplus b_{3}, \\ \text { Paul only read } b_{1} \oplus b_{3} \oplus b_{4}, \\ \text { Paul only read } b_{1} \oplus b_{2} \oplus b_{4}, \\ \text { Paul only read } b_{2} \oplus b_{3} \oplus b_{4}\end{array}\right\}$

This meaning is merely the union of the sets for the sentences with The New York Times and the sentences with some of the the books, which is then closed with one $\exists$ operator. Once again, the problem with the standard analysis does not arise, since we exhaustify each of these alternatives separately before applying existential closure.

\footnotetext{
${ }^{6}$ It is crucial for this analysis that the existential force of $o r$, like that of the indefinites, be able to scope above the exhaustive operator. See Alonso-Ovalle (2005) for more discussion of disjunction in Alternative Semantics.
} 


\section{Further Issues}

\subsection{Order of Operators}

One question that often arises in reference to null operators is their distribution. The simplest answer is that the operator, Exh in this case, can appear anywhere where it is not prevented by some outside factor. To maintain this position, it is necessary to show what happens when the exhaustive operator appears in positions other than those shown above.

As it turns out, many positions for Exh simply fail due to incompatible types: Exh requires a set of propositions, so it cannot combine with, for instance, a $D P$ or a $P P$, or any other phrase whose meaning does not evaluate to a set of propositions.

One position where Exh could conceivably apply, however, is before a sentence where the $\exists$ has already been added. ${ }^{7}$ This possibility does not seem to cause any trouble, though. In simple cases, this "wrong" order derives the same meaning as the right order:

a. Exh $\exists$ Paul read The New York Times.

b. Paul only read The New York Times.

In more complex cases, the meaning derived is contradictory:

a. Exh $\exists$ Paul read three books.

b. One of these statements is true:

$$
\begin{aligned}
& \left\{\begin{array}{l}
\text { Paul read } b_{1} \oplus b_{2} \oplus b_{3}, \\
\text { Paul read } b_{1} \oplus b_{3} \oplus b_{4}, \\
\text { Paul read } b_{1} \oplus b_{2} \oplus b_{4}, \\
\text { Paul read } b_{2} \oplus b_{3} \oplus b_{4}
\end{array}\right\} \\
& \text { And all of these statements are false: } \\
& \left\{\begin{array}{l}
\text { Paul read } b_{1}, \\
\text { Paul read } b_{2}, \\
\text { Paul read } b_{3}, \\
\text { Paul read } b_{4}, \\
\text { Paul read } b_{1} \oplus b_{2}, \\
\text { Paul read } b_{2} \oplus b_{3}, \\
\text { Paul read } b_{3} \oplus b_{4}, \\
\text { Paul read } b_{1} \oplus b_{4}, \\
\text { Paul read } b_{1} \oplus b_{2} \oplus b_{3}, \\
\text { Paul read } b_{1} \oplus b_{3} \oplus b_{4}, \\
\text { Paul read } b_{1} \oplus b_{2} \oplus b_{4}, \\
\text { Paul read } b_{2} \oplus b_{3} \oplus b_{4} \\
\text { Paul read } b_{1} \oplus b_{2} \oplus b_{3} \oplus b_{4}
\end{array}\right\}
\end{aligned}
$$

\footnotetext{
${ }^{7}$ Notice that as defined above, $\exists$ returns a set of propositions; the assumption is that the interpretation procedure can handle such singleton sets of propositions.
} 
Since the prejacent ( $\exists$ Paul read three books) does not entail any of the statements in the focus set, they are all false according to the definition of Exh. However if they are all false, then the prejacent itself cannot be true. Assuming that such contradictions are avoided in the semantic system, this derivation would be ruled out.

\subsection{Conclusions and Extensions}

This paper has presented a new way to analyze scalar implicatures that solves some challenges to other theories. The proposal uses well-known linguistic machinery to build a new theory: a focus set to define alternatives instead of Horn Scales, existential closure to get the correct scope, and contradiction avoidance to motivate this scope.

This proposal suggests many possible extensions or areas of further study. I end the paper with a short list of such questions. What happens when an exhaustified sentence is embedded under a modal or negation? What is the focus set for an embedded sentence? How is it different from the focus set for the matrix sentence? Is there a difference between the questions What did Paul read last night and How many books did Paul read last night? What is the difference between Exh and the overt word only?

\section{References}

Alonso-Ovalle, Luis: 2005, 'Or Preserves Semantic Identity: Disjunction in Alternative Semantics'. LSA Summer Institute Handout.

Chierchia, Gennaro: 2002, 'Scalar Implicature, Polarity Phenomena, and the Syntax/Pragmatics Interface'. Ms., University of Milan Bicocca.

Collingwood, R G: 1940, 'An Essay in Metaphysics'. Oxford University Press.

von Fintel, K.: 1995, 'A Minimal Theory of Adverbial Quantification'. Unpublished draft Ms. MIT, Cambridge, March.

Fox, Danny: 2004, 'Implicatures and Exhaustivity'. Handout from class at USC.

Fox, Danny: 2006, 'Free Choice and the Theory of Scalar Implicatures'. Ms., MIT. Groenendijk, Jeroen and Mertin Stokhof: 1984, Studies in the Semantics of Questions and the Pragmatics of Answers, $\mathrm{PhD}$ dissertation, University of Amsterdam.

Heim, Irene: 1982, The Semantics of Definite and Indefinite Noun Phrases, $\mathrm{PhD}$ dissertation, Univeristy of Massachusetts, Amherst.

Heim, Irene and Angelika Kratzer: 1998, Semantics in Generative Grammar. Oxford: Blackwell.

Horn, Laurence: 1972, On the Semantic Properties of Logical Operators in English, $\mathrm{PhD}$ dissertation, UCLA.

Kratzer, Angelika: 1989, 'An Investigation of the Lumps of Thought', Linguistics and Philosophy 12, 607-53. 
Kratzer, Angelika: 2005, 'LSA Class Notes'.

Kratzer, Angelika and Junko Shimoyama: 2002, 'Indeterminate Pronouns: The View from Japanese', in Y. Otsu (ed.), The Proceedings of the Third Tokyo Conference on Psycholinguistics, 1-25. Tokyo: Hituzi Syobo.

Krifka, Manfred: 1995, 'The Semantics and Pragmatics of Polarity Items', Linguistic Analysis 25, 209-257.

Krifka, Manfred: 1999, 'At Least Some Determiners aren't Determiners', in K. Turner (ed.), The Semantics/Pragmatics Interface from Different Points of View (Current Research in the Semantics/Pragmatics Interface 1), 257291. Elsevier Science B.V.

Link, Godehard: 1983, 'The Logical Analysis of Plurals and Mass Terms: A Lattice-Theoretical Approach', in R. Bauerle, C. Schwartze, and A. von Stechow (eds.), Meaning, Use and Interpretation in Language, 302-323. Berlin: Mouton de Gruyter.

Menendez-Benito, Paula: 2005, 'LSA Class Notes'.

Rooth, Mats: 1992, 'A Theory of Focus Interpretation', Natural Language Semantics 1, 75-116.

Rooth, Mats and Barbara Partee: 1982, 'Conjunction, Type Ambiguity and Wide Scope Or', in D. Flickinger, M. Marken, and N. Wiegand (eds.), Proceedings of the First West Coast Conference on Formal Linguistics. Stanford University.

Sauerland, Uli: 2004, 'Scalar Implicatures in Complex Sentences', Linguistics and Philosophy 27, 271-316. 